\title{
A retrospective analysis of weight loss associated with the Orbera intragastric balloon at a single bariatric center
}

\author{
Vamsi Reddy ${ }^{*}$, Nitish Sood ${ }^{1}$, Jennifer $\mathrm{Hua}^{2}$ and Christopher Ibikunle ${ }^{3}$ \\ ${ }^{1}$ Medical College of Georgia, Augusta University, Georgia, USA \\ ${ }^{2}$ Georgia Campus-Philadelphia College of Osteopathic Medicine, Philadelphia, Pennsylvania, USA \\ ${ }^{3}$ Georgia SurgiCare, Ideal Body Institute, Atlanta, Georgia, USA
}

\begin{abstract}
Retrospective Study: An assessment of weight loss and safety profile of orbera intragastric balloon system

Background: Lifestyle modification and dietary management have proven to be ineffective in the treatment of obesity. ORBERA Intragastric Balloon (IGB) system, a treatment modality approved by the US Food and Drug Administration has recently become available commercially for the treatment of refractory obesity in patients with BMI of 35-40. Data on the effectiveness and accommodative adverse effect of ORBERA IGB are however limited. The objective of this study is to measure the effect of IGB on weight loss, assess the accommodative adverse event safety profile, and examine factors associated with accommodative symptoms such as nausea and vomiting.
\end{abstract}

Methods: A review of records of 22 patients treated using ORBERA in a private clinic from September 2016 to January 2018 was conducted. The balloons were filled with $400-600 \mathrm{~mL}$ of saline solution. The IGB was placed and removed endoscopically over a treatment period of 6 months.

Results: The sample size comprised of 18 (81.82\%) females and 4 (18.18\%) males with a mean age of 49.23 (range 21 - 76 years). The most common comorbidities in this population were gastroparesis (4, 20\%), hiatal hernia (6, 29\%), DM (3, 15\%), and cholecystitis (2, 10\%). Baseline mean weight was $239.26 \mathrm{lb}$ (range 158 $\mathrm{lb}-323 \mathrm{lb}$ ), baseline mean BMI was 39.48 (range $29.85-48.90$ ). The mean end of treatment weight was $182.2 \mathrm{lb}$ (range $134 \mathrm{lb}-279 \mathrm{lb}$ ) with a mean weight loss of $32.2 \mathrm{lb}$ (range $16 \mathrm{lb}-48 \mathrm{lb}$ ) and a mean BMI 30.79 (range $25.3-40.2$ ) at end of the 6 months treatment period. No serious adverse events were observed during the endoscopic placement and removal of the system. The most frequent accommodative adverse events were nausea 13 (65\%), vomiting 12 (60\%), reflux/GERD 8 (40\%). No significant characteristics associated with the accommodative side effects (e.g. nausea and vomiting) were discernible.

Conclusion: The findings suggest that ORBERA IGB is an effective, safe and reasonably well-tolerated management option for obesity as significant weight loss was found consistently in the study population. However, further study is recommended for a better understanding of the accommodative symptoms associated with the IGB system.

\section{Background}

Obesity is a global epidemic - one that no country has been able to tackle effectively [1]. In the United States, obesity rates have been increasing since the 1980s [2]. The prevalence of obesity in adults over the age of 20 has steadily risen over the last decade, reaching $39.8 \%$ in 2017. This is estimated to reach approximately $42 \%-51 \%$ by $2030[3,4]$. Even a one percent decrease from this predicted value would correlate with a $\$ 4.0( \pm \$ 0.5)$ billion reduction in obesity-attributable medical spending by 2020 [4]. Thus, highlighting the importance of finding solutions to this epidemic.

Additionally, obesity's link with decreased life expectancy is wellestablished. A prospective cohort study with over 60,000 participants found that among non-smokers at age 50, obese populations have a two to three-fold increase in mortality risk when compared to nonobese populations [5]. Traditional weight-loss goals aim for a five to ten percent decrease in body weight which has been shown to slow the onset of obesity-related co-morbidities such as type 2 diabetes [6,7].

As the population of obese individuals in the United States continues to grow, it becomes increasingly important to evaluate the different treatment options and their roles in patient care. Physical exercise, energy-restricted diets, and behaviour modification remain the first-line treatment options for almost all patients. These play a critical role in not only treatment but also prevention [8]. Pharmacotherapy is often used as a secondary option for patients in whom lifestyle changes have been unsuccessful. Surgical alternatives, including adjustable gastric banding and gastric bypass procedures, have long been demonstrated to be more effective at inducing weight loss in patients who are severely obese [9]. Despite the proven efficacy of bariatric surgery, very few eligible candidates with morbid obesity choose to undergo surgical weight-loss procedures [9,10]. Many prospective patients have shied away from surgical options due to fear of invasive procedures and potential complications [6]; for this group, endoscopic alternatives may appear more attractive. Additional market segments include severely ill patients who are poor surgical candidates as well as very obese patients $\left(\mathrm{BMI}>40 \mathrm{~kg} / \mathrm{m}^{2}\right.$ or BMI $>35 \mathrm{~kg} / \mathrm{m}^{2}$ with

*Correspondence to: Vamsi Reddy, Medical College of Georgia, Augusta University, Georgia, USA, E-mail: VAREDDY@augusta.edu

Key words: intragastric balloon, orbera, weight loss, bariatric surgery

Received: February 26, 2020; Accepted: March 09, 2020; Published: March 13, 2020 
obesity-associated comorbidities) for whom a moderate preoperative weight loss may reduce surgical complications $[6,11]$ We present a retrospective study of 22 patients with BMIs ranging from 30 to 49 who underwent endoscopic placement of Orbera Intragastric Balloons.

\section{Methods}

A review was conducted of the 22 patient records for those undergoing placement of the Orbera Intragastric Balloon (IGB) between September 2016-January 2018. No super-obese patients were included $\left(\mathrm{BMI}>50 \mathrm{~kg} / \mathrm{m}^{2}\right)$ within the study. All had previously failed to achieve desired levels of weight loss using traditional weight control programs. The IGBs were filled with $400 \mathrm{~mL}-600 \mathrm{~mL}$ of saline solution. For each patient, the IGBs were placed and removed endoscopically after a treatment period of six months.

\section{Results}

The sample size comprised of 18 (81.82\%) females and 4 (18.18\%) males with a mean age of 49.23 (range $21-76$ years). The most common comorbidities in this population were gastroparesis $(4,20 \%)$, hiatal hernia (6,29\%), diabetes mellitus (3,15\%), and cholecystitis $(2,10 \%)$. Baseline mean weight was $239.26 \mathrm{lb}$. (range $158 \mathrm{lb} .-323 \mathrm{lb}$.). The mean weight loss was 32.2 (range $16 \mathrm{lb}$. $-48 \mathrm{lb}$.), with a mean end of treatment weight of $207.06 \mathrm{lb}$. Weight loss changes are represented in figure 1. The baseline mean BMI was $39.48 \mathrm{lb}$. (range $29.85 \mathrm{~kg} / \mathrm{m}^{2}-42.24 \mathrm{~kg} / \mathrm{m}^{2}$ ). The mean BMI decrease was $5.31 \mathrm{~kg} / \mathrm{m}^{2}$, with a mean end of treatment BMI of $34.17 \mathrm{~kg} / \mathrm{m}^{2}$. This represents a $13.5 \%$ drop in weight over the 6-month treatment period. BMI changes are illustrated in figure 2.

No serious adverse events were observed during the endoscopic placement and removal of the balloon. The most frequent accommodative adverse events were nausea $(13,65 \%)$, vomiting (12, $60 \%)$, reflux/GERD $(8,40 \%)$. No significant characteristics associated with the accommodative side effects (e.g. nausea and vomiting) were discernible. Sample data is shown in table 1.

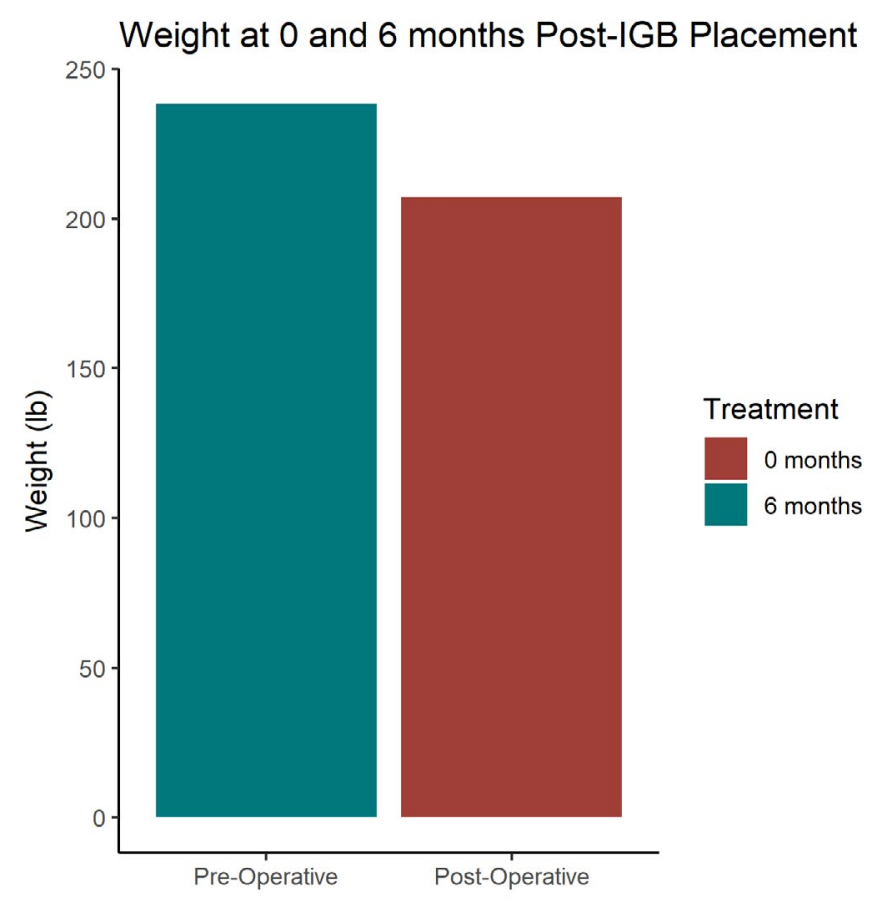

Figure 1. Drop in weight at time points 0 months and 6 months after Orbera IGB placement

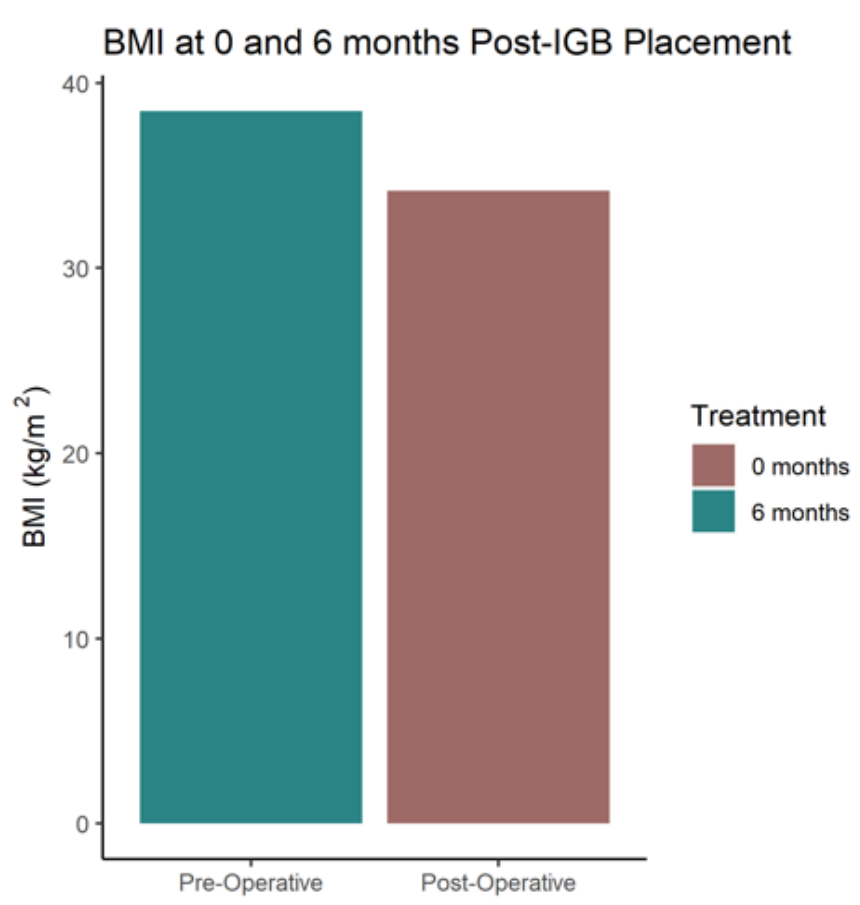

Figure 2. Drop in BMI at time points 0 months and 6 months after Orbera IGB placement

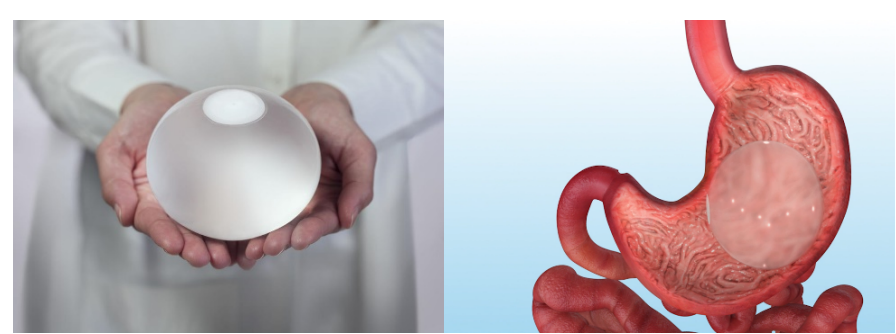

Figure 3. Illustration of orbera balloon outside and inside patient

Table 1. Sample data collected for patients who underwent orbera procedure

\begin{tabular}{|l|c|c|c|c|c|c|c|c|c|}
\hline & Sex & Age & $\begin{array}{c}\text { Starting } \\
\text { Weight }\end{array}$ & $\begin{array}{c}\text { Ending } \\
\text { Weight }\end{array}$ & $\begin{array}{c}\text { Weight } \\
\text { Loss }\end{array}$ & $\begin{array}{c}\text { Starting } \\
\text { BMI }\end{array}$ & $\begin{array}{c}\text { Ending } \\
\text { BMI }\end{array}$ & $\begin{array}{c}\text { BMI } \\
\text { Change }\end{array}$ & $\begin{array}{c}\text { Height } \\
\text { (in) }\end{array}$ \\
\hline Patient A & F & 24 & 212.9 & 176.7 & 36.2 & 37.58 & 31.19 & 6.39 & 63.108 \\
\hline Patient B & F & 29 & 186.7 & 157.4 & 29.3 & 34.98 & 29.49 & 5.49 & 61.255 \\
\hline Patient C & F & 46 & 259.8 & 212.5 & 47.3 & 40.12 & 32.82 & 7.30 & 67.471 \\
\hline Patient D & F & 51 & 280 & 255.4 & 24.6 & 42.99 & 39.21 & 3.78 & 67.666 \\
\hline Patient E & F & 57 & 233.7 & 200.2 & 33.5 & 39.19 & 33.57 & 5.62 & 64.747 \\
\hline Patient F & M & 58 & 266.2 & 226.7 & 39.5 & 40.91 & 34.84 & 6.07 & 67.634 \\
\hline Patient G & F & 64 & 244.8 & 202.5 & 42.3 & 39.16 & 32.39 & 6.77 & 66.292 \\
\hline Patient H & F & 68 & 204.4 & 170.2 & 34.2 & 37.89 & 31.55 & 6.34 & 61.582 \\
\hline
\end{tabular}

\section{Conclusion}

Treatment with Orbera Intragastric Balloon (Figure 3) coupled with changes in diet and exercise induced an average weight loss of $13.5 \%$. This difference was not statistically significant across different ages or genders and represented a slightly greater decrease in weight than that found in a recent meta-analysis [12]. Significant weight loss was consistently found within the study population. Overall, this suggests Orbera IGB is an effective, safe, and well-tolerated management option for obesity. However, further study is recommended for a better understanding of the accommodative symptoms associated with the IGB system. 


\section{References}

1. Flegal KM, Carroll MD, Kuczmarski RJ, Johnson CL (1998) Overweight and obesity in the United States: prevalence and trends, 1960-1994. Int J Obes Relat Metab Disord 22: 39-47. [Crossref]

2. Ng M, Fleming T, Robinson M, Thomson B, Graetz N, et al. (2014) Global, regional, and national prevalence of overweight and obesity in children and adults during 1980 2013: a systematic analysis for the Global Burden of Disease Study 2013. Lancet 384: 766-781. [Crossref]

3. Health-Statistics NCf. Obesity and Overweight. 2017; https://www.cdc.gov/nchs/ fastats/obesity-overweight.htm. Accessed November 23, 2019.

4. Finkelstein EA, Khavjou OA, Thompson H, Trogdon JG, Pan L, et al. (2012) Obesity and severe obesity forecasts through 2030. Am J Prev Med 42: 563-570. [Crossref]

5. Adams KF, Schatzkin A, Harris TB, Kipnis V, Mouw T, et al. (2006) Overweight, obesity, and mortality in a large prospective cohort of persons 50 to 71 years old. $N$ Engl J Med 355: 763-778. [Crossref]

6. Mathus-Vliegen EM (2014) Endoscopic treatment: the past, the present and the future. Best Pract Res Clin Gastroenterol 28: 685-702. [Crossref]
7. National Institute for Health and Clinical Excellence: Guidance (2006) Obesity: The Prevention, Identification, Assessment and Management of Overweight and Obesity in Adults and Children. London: National Institute for Health and Clinical Excellence (UK). [Crossref]

8. NHLBI Obesity Education Initiative Expert Panel on the Identification E, and Treatmen of Obesity in Adults (US). Clinical Guidelines on the Identification, Evaluation, and Treatment of Overweight and Obesity in Adults. National Heart, Lung, and Blood Institute1998. 98-4083.

9. Maggard MA, Shugarman LR, Suttorp M, Maglione M, Sugerman HJ, et al. (2005) Meta-analysis: surgical treatment of obesity. Ann Intern Med 142: 547-559. [Crossref]

10. Buchwald H, Oien DM (2013) Metabolic/bariatric surgery worldwide 2011. Obes Surg 23: 427-436. [Crossref]

11. Weiner R, Gutberlet H, Bockhorn H (1999) Preparation of extremely obese patients for laparoscopic gastric banding by gastric-balloon therapy. Obes Surg 9: 261-264. [Crossref]

12. Imaz I, Martinez-Cervell C, Garcia-Alvarez EE, Sendra-Gutierrez JM, GonzalezEnriquez J (2008) Safety and effectiveness of the intragastric balloon for obesity. A meta-analysis. Obes Surg 18: 841-846. [Crossref]

Copyright: $(\mathbb{2} 2020$ Reddy V. This is an open-access article distributed under the terms of the Creative Commons Attribution License, which permits unrestricted use, distribution, and reproduction in any medium, provided the original author and source are credited. 